\title{
Facial nerve paralysis postparotidectomy: A retrospective review of the prevalence and risk factors at a tertiary center
}

\author{
Shahad T. Ghandoura ${ }^{1}$, Mahmood Z. Al-Madani ${ }^{2}$, Qusai A. Tawakul ${ }^{3}$, Nada J. Farsi ${ }^{4}$, Rolina K. Alwassia ${ }^{5}$, Mazin A. \\ Merdad $^{1}$, Talal A. Al-khatib ${ }^{1}$, Khalid B. Alghamdi ${ }^{1}$, Hani Z. Marzouki*1 \\ ${ }^{1}$ Department of Otolaryngology-Head \& Neck Surgery, Faculty of Medicine, King Abdulaziz University, Jeddah, Saudi Arabia \\ ${ }^{2}$ Faculty of Medicine, Batterjee Medical College, Jeddah, Saudi Arabia \\ ${ }^{3}$ Faculty of Medicine, Umm Al-Qura University, Makkah, Saudi Arabia \\ ${ }^{4}$ Department of Dental Public Health, Faculty of Dentistry, King Abdulaziz University, Jeddah, Saudi Arabia \\ ${ }^{5}$ Department of Radiology, Faculty of Medicine, King Abdulaziz University, Jeddah, Saudi Arabia
}

Received: June 8, 2017

DOI: $10.5430 / \operatorname{css} . v 3 n 4 p 1$
Accepted: August 15, 2017

URL: https://doi.org/10.5430/css.v3n4p1
Online Published: August 30, 2017

\begin{abstract}
Objective: Facial nerve paralysis is one of the most devastating complications after parotid gland surgery. We aimed to determine the prevalence and risk factors of facial palsy after parotidectomy.

Methods: We performed a retrospective review of the data from 54 patients who underwent parotid surgery between 2004 and 2015 at a tertiary medical care center. The prevalence of facial nerve paralysis and possible risk factors (demographic characteristics, tumor characteristics, and operative factors) associated with postoperative paralysis were assessed. Categorical variables were evaluated using the Fisher's exact test, and a two-tailed $t$-test was used to assess the associations between continuous and binary outcome variables.

Results: The postparotidectomy prevalence of temporary and permanent facial nerve paralysis were $26 \%$ and $13 \%$, respectively. Tumors involving both lobes were significantly associated with permanent facial nerve paralysis $(p=.048)$. Long operative duration (> 164 minutes) was associated with both temporary and permanent facial nerve paralysis $(p=.040)$.

Conclusions: Operative factors such as operative duration and tumor characteristics such as bilobal involvement increased the risk of postparotidectomy facial nerve paralysis. Such factors should be considered to reduce the risk of palsy in patients undergoing parotidectomy.
\end{abstract}

Key Words: Parotidectomy, Facial nerve paralysis, Palsy, Risk factors, Parotid tumor

\section{INTRODUCTION}

Salivary gland tumors account for 5\% of all head and neck tumors and most $(75 \%)$ occur in the parotid gland. ${ }^{[1]} \mathrm{Up}$ to $90.47 \%$ of salivary gland tumors are benign, and $79.36 \%$ are located within the superficial lobe. ${ }^{[2]}$ The treatment of choice is usually surgery; ${ }^{[3,4]}$ however, because of anatomical proximity to the facial nerves, ${ }^{[5]}$ permanent facial nerve injury is one of the most devastating surgical complications of a parotidectomy. Facial nerve injury can negatively affect a patient's quality of life, causing cosmetic defects and

\footnotetext{
* Correspondence: Hani Z. Marzouki; Email: hanimarzouki@gmail.com; Address: Department of Otolaryngology-Head \& Neck Surgery, Faculty of Medicine, King Abdulaziz University, P.O. Box 80200, Jeddah 21589, Saudi Arabia.
} 
psychological distress. ${ }^{[6]}$

Permanent and temporary facial nerve injuries after parotidectomy have been estimated to occur in $4 \%$ and $18 \%$ of cases, respectively. ${ }^{[7]}$ Several factors have been associated with facial nerve injury including a history of malignant pathology, deep lobe involvement, lack of nerve monitoring, use of diathermy, surgical techniques, revision surgery, additional neck dissection, and diabetes. ${ }^{[8-14]}$

In the present study, we aimed to determine the prevalence of postparotidectomy facial nerve paralysis and to identify risk factors associated with its development.

\section{Patients AND Methods}

All subjects who underwent parotidectomy at King Abdulaziz University Hospital between January 2004 and May 2015 were identified. Information regarding demographic factors, comorbidities, tumor depth, tumor size, and histopathological diagnoses were collected. Additionally, we collected information about the surgical technique performed, surgeons' experience level, operative duration, and the uses of magnifying lenses (loupes), electromyography (EMG) for nerve monitoring, a nerve stimulator, and the harmonic scalpel. Permanent facial nerve paralysis was defined as that persisting for $>1$ postoperative year.

The study outcome was facial nerve paralysis, which was assessed using two formats as (1) binary (absent and either temporary or permanent paralysis), and (2) categorical (no paralysis, temporary paralysis, or permanent paralysis). The present study was approved by the King Abdulaziz University (HA-02-J-008) Research Ethics Board.

Associations between variables (tumor depth, histopathological diagnoses, the use of loups, EMG use, nerve stimulator use, and the type of facial nerve dissection) and binary facial nerve paralysis were assessed. The relationships between the remaining factors and the three-category outcome variable were then examined.

Categorical variables were evaluated using Fisher's exact test. A two-tailed t-test was used to assess the associations between continuous and binary outcome variables. A $p$-value of $<.05$, indicated statistical significance. Statistical analyses were conducted using Stata 12.1 (StataCorp LP, College Station, Texas, USA).

\section{RESULTS}

Sixty-five parotidectomies were performed at King Abdulaziz University Hospital during the study period. Eleven subjects were excluded because of missing data on facial nerve paralysis. The final analysis included 54 patients. Patient 2 and lesion characteristics are shown in Table 1. The majority of the lesions affected the superficial lobe. The prevalence rate of postoperative temporary facial nerve paralysis was double that of permanent facial paralysis. The histopathological diagnoses of the lesions are shown in Table 2. Forty-five tumors were benign, and pleomorphic adenomas were the most common pathological subtype.

Risk factor analyses for postparotidectomy facial nerve paralysis are shown in Table 3. There was a significant association between tumor depth and permanent facial nerve paralysis. The majority of the patients with superficial lobe lesions did not develop permanent facial nerve paralysis, whereas there was a high prevalence of permanent facial nerve paralysis in those with lesions in both the superficial and deep lobes (both lobes). Cancerous lesions were more likely to be associated with permanent facial nerve paralysis, although the association did not reach significance $(p=.06)$. None of the other variables studied had a significant association with postoperative permanent facial nerve paralysis in the binary outcome analyses (see Table 3 ).

For the categorical outcome analyses (see Table 4), tumor depth and operative duration were significantly associated with facial nerve paralysis. Permanent facial paralysis was associated with lesions involving both the deep and superficial lobes, whereas no paralysis or temporary paralysis was seen in the majority of patients with superficial tumors alone. A longer operative duration (> 164 minutes) was significantly associated with both temporary and permanent facial nerve paralysis. Diabetes, tumor size, the use of the harmonic scalpel, and surgeons' years of experience were not associated with postparotidectomy facial nerve paralysis.

\section{Discussion}

Parotid tumors, whether benign or malignant, often require parotidectomy surgery. ${ }^{[3,4]}$ In the present study, the prevalence of and risk factors associated with facial nerve paralysis after parotidectomy were evaluated. Tumor depth and operative duration were significantly associated with facial nerve paralysis.

We observed significant associations of temporary and permanent facial nerve paralysis with the resection of lesions that affected both the lobes concomitantly, which was concordant with previous studies. ${ }^{[8,9,11,12]}$ In addition, long operative duration was also significantly associated with facial nerve paralysis as previously reported. ${ }^{[7,10]}$ In previous studies, malignant lesions were more likely to be associated with permanent facial nerve paralysis. ${ }^{[9-11]}$ The present study revealed a similar tendency although the findings did not reach significance. The associations of these factors with facial 
nerve paralysis might be explained partially by the complexity of excising deep lobe and malignant parotid tumors.

Table 1. Patient and lesion characteristics

\begin{tabular}{|c|c|}
\hline Variable & $\mathbf{N}(\%)$ \\
\hline \multicolumn{2}{|l|}{ Demographic factors } \\
\hline \multicolumn{2}{|l|}{ Age } \\
\hline - mean $(S D)$ & $41.35(17.40)$ \\
\hline \multicolumn{2}{|l|}{ Sex } \\
\hline - Male & $26(48.15)$ \\
\hline - Female & $28(51.85)$ \\
\hline \multicolumn{2}{|l|}{ Medical factors } \\
\hline \multicolumn{2}{|l|}{ Diabetes } \\
\hline - No & $42(80.77)$ \\
\hline - Yes & $10(19.23)$ \\
\hline \multicolumn{2}{|l|}{ Lesion nature } \\
\hline \multicolumn{2}{|l|}{ Tumor size } \\
\hline - $\leq 4 \mathrm{~cm}$ & $18(52.94)$ \\
\hline - $>4 \mathrm{~cm}$ & $16(47.06)$ \\
\hline \multicolumn{2}{|l|}{ Tumor depth } \\
\hline - Superficial lobe & $37(69.81)$ \\
\hline - Deep lobe & $5(9.43)$ \\
\hline - Both lobes & $11(20.75)$ \\
\hline \multicolumn{2}{|l|}{ Histopathology } \\
\hline - No cancer & $45(84.91)$ \\
\hline - Cancer & $8(15.09)$ \\
\hline \multicolumn{2}{|c|}{ Surgical technique and physicians' experience } \\
\hline \multicolumn{2}{|c|}{ Use of loupes } \\
\hline - No & $31(57.41)$ \\
\hline - Yes & $23(42.59)$ \\
\hline \multicolumn{2}{|l|}{ Use of EMG } \\
\hline - No & $40(75.47)$ \\
\hline - Yes & $13(24.53)$ \\
\hline \multicolumn{2}{|c|}{ Use of a nerve stimulator } \\
\hline • No & $0(0)$ \\
\hline - Yes & $34(100)$ \\
\hline \multicolumn{2}{|c|}{ Use of the harmonic scalpel } \\
\hline - No & $50(92.59)$ \\
\hline - Yes & $4(7.41)$ \\
\hline \multicolumn{2}{|c|}{ Type of facial nerve dissection } \\
\hline - Anterograde & $7(17.50)$ \\
\hline - Retrograde & $31(77.50)$ \\
\hline - Both & $2(5.00)$ \\
\hline \multicolumn{2}{|l|}{ Operation duration } \\
\hline$\bullet \leq 164 \mathrm{~min}$ & $29(53.70)$ \\
\hline - > $164 \mathrm{~min}$ & $25(46.30)$ \\
\hline \multicolumn{2}{|c|}{ Postoperative facial nerve paralysis } \\
\hline - None & $33(61.11)$ \\
\hline - Temporary & $14(25.93)$ \\
\hline - Permanent & $7(12.96)$ \\
\hline \multicolumn{2}{|c|}{ Physicians' experience } \\
\hline$\bullet \leq 25$ years & $33(61.11)$ \\
\hline - > 25 years & $21(38.89)$ \\
\hline
\end{tabular}

Note. Some cells do not add up to the total because of missing values
Table 2. Histopathological diagnoses for parotidectomy among the subjects

\begin{tabular}{ll}
\hline Histopathological diagnosis & N (\%) \\
\hline Pleomorphic adenoma or mixed tumor & $24(45.28)$ \\
Warthin's tumor (papillary cystadenoma & $13(24.53)$ \\
lymphomatosum or adenolymphoma) & $2(3.77)$ \\
Benign lymphoepithelial cell & $2(3.77)$ \\
Basal cell adenoma & $1(1.89)$ \\
Mucoepidermoid carcinoma high grade & $1(1.89)$ \\
Mucoepidermoid carcinoma low grade & $3(5.66)$ \\
Acinic cell carcinoma & $1(1.89)$ \\
Adenocarcinoma & $1(1.89)$ \\
SCC & $5(1.89)$ \\
\hline Other &
\end{tabular}

Note. Diagnosis information was missing for one patient

Previous studies indicated the importance of tumor size regarding the rate of facial nerve paralysis, with an increased risk for large tumors. ${ }^{[7,10-12]}$ However, the present study did not observe any differences in paralysis rates according to tumor size.

The benefit of continuous nerve monitoring using EMG during parotidectomy has not been confirmed. Sood et al. showed that EMG decreased the risk of facial nerve injury during surgery, whereas Grosheva et al. found that EMG did not decrease the incidence of facial nerve injury. ${ }^{[13,15]}$ In the present study, EMG monitoring was not associated with the rate of temporary or permanent facial nerve injury.

Retrograde dissection guided by the buccal or cervical nerve branch has been associated with a lower risk of facial nerve palsy and decreased operative time compared with anterograde dissection. ${ }^{[16,17]}$ A higher risk of developing facial nerve paralysis has also been noted in patients with advanced age. ${ }^{[7]}$ Unexpectedly, neither of these factors affected paralysis rates in the present study, although this might be due to the small sample size employed.

The present study showed that the use of harmonic scalpel was not associated with a reduction in facial nerve injury. Muhanna et al. showed that, compared with diathermy, the use of the harmonic scalpel decreased temporary facial nerve paralysis. ${ }^{[14]}$ However, the harmonic scalpel was utilized in a very small proportion of patients in the present study, which might explain our inability to detect any effect on facial nerve paralysis.

Although not the case in the present study, previous studies have suggested that patients with diabetes have an increased susceptibility to temporary facial palsy. ${ }^{[8]}$ It is noteworthy that physician' years of experience and the use of surgical loupes also had no effect on postoperative facial nerve status. 
Table 3. Associations of selected factors with postparotidectomy facial nerve paralysis

\begin{tabular}{|c|c|c|c|}
\hline Variable & $\begin{array}{l}\text { Permanent facial nerve } \\
\text { paralysis }(n=7)\end{array}$ & $\begin{array}{l}\text { Absent or temporary facial } \\
\text { nerve paralysis }(n=47)\end{array}$ & $p$-value \\
\hline \multicolumn{4}{|l|}{ Demographic factors } \\
\hline \multicolumn{4}{|l|}{ Age } \\
\hline - mean $(S D)$ & $39.57(20.35)$ & $41.62(17.08)$ & $.775^{*}$ \\
\hline \multicolumn{4}{|l|}{ Sex } \\
\hline - Male & $4(57.14)$ & $22(46.81)$ & $.699^{\#}$ \\
\hline - Female & $3(42.86)$ & $25(53.19)$ & \\
\hline \multicolumn{4}{|l|}{ Lesion nature } \\
\hline \multicolumn{4}{|l|}{ Tumor depth } \\
\hline - Superficial lobe & $3(42.86)$ & 34 (73.91) & $.048^{\#}$ \\
\hline - Deep lobe & $0(0)$ & $5(10.87)$ & \\
\hline - Both lobes & $4(57.14)$ & $7(15.22)$ & \\
\hline $\begin{array}{l}\text { Histopathology } \\
\text { - No cancer }\end{array}$ & $4(57.14)$ & 41 (89.13) & $.061^{\#}$ \\
\hline - Cancer & $3(42.86)$ & $5(10.87)$ & \\
\hline \multicolumn{4}{|l|}{ Surgical technique } \\
\hline \multicolumn{4}{|l|}{ Use of loupes } \\
\hline - No & $5(71.43)$ & $26(55.32)$ & $.685^{\#}$ \\
\hline - Yes & $2(28.57)$ & $21(44.68)$ & \\
\hline \multicolumn{4}{|l|}{ Use of EMG } \\
\hline - No & $5(71.43)$ & 35 (76.09) & $1.000^{\#}$ \\
\hline - Yes & $2(28.57)$ & $11(23.91)$ & \\
\hline \multicolumn{4}{|c|}{ Use of a nerve stimulator } \\
\hline - No & $0(0)$ & $0(0)$ & --- \\
\hline - Yes & $2(100)$ & $32(100)$ & \\
\hline \multicolumn{4}{|c|}{ Type of facial nerve dissection } \\
\hline - Anterograde & $1(25)$ & $6(16.67)$ & $1.000^{\#}$ \\
\hline - Retrograde & $3(75)$ & $28(77.78)$ & \\
\hline - Both & $0(0)$ & $2(5.56)$ & \\
\hline
\end{tabular}

Note. ${ }^{*}$ Diagnosis information was missing for one patient; ${ }^{\#}$ Fisher's exact test was used; Two-sample $t$-test was used; Some cells do not add up to the total because of missing values

Table 4. Associations of selected factors with temporary and permanent postparotidectomy facial nerve paralysis

\begin{tabular}{|c|c|c|c|c|}
\hline Variable & $\begin{array}{l}\text { No facial nerve } \\
\text { paralysis }(n=33)\end{array}$ & $\begin{array}{l}\text { Temporary facial nerve } \\
\text { paralysis }(\mathrm{n}=14)\end{array}$ & $\begin{array}{l}\text { Subjects with permanent } \\
\text { facial nerve paralysis }(n=7)\end{array}$ & $p$-value \\
\hline \multicolumn{5}{|l|}{ Medical factors } \\
\hline \multicolumn{5}{|l|}{ Diabetes } \\
\hline - No & $24(75.0)$ & $12(85.71)$ & $6(100)$ & .457 \\
\hline - Yes & $8(25.0)$ & $2(14.29)$ & $0(0)$ & \\
\hline \multicolumn{5}{|l|}{ Lesion nature } \\
\hline \multicolumn{5}{|l|}{ Tumor size } \\
\hline - $\leq 4 \mathrm{~cm}$ & $13(65.00)$ & $3(27.27)$ & $2(66.67)$ & .108 \\
\hline \multicolumn{5}{|l|}{ Tumor depth } \\
\hline - Superficial lobe & $26(81.25)$ & $8(57.14)$ & $3(42.86)$ & .041 \\
\hline - Deep lobe & $2(6.25)$ & $3(21.43)$ & $0(0)$ & \\
\hline - Both lobes & $4(12.50)$ & $3(21.43)$ & $4(57.14)$ & \\
\hline \multicolumn{5}{|c|}{ Surgical technique and physicians' experience } \\
\hline \multicolumn{5}{|c|}{ Operative duration } \\
\hline$\bullet \leq 164 \min$ & $21(65.62)$ & $5(35.71)$ & $1(16.67)$ & .040 \\
\hline • > $164 \min$ & $11(34.38)$ & $9(64.29)$ & $5(83.33)$ & \\
\hline \multicolumn{5}{|c|}{ Use of the harmonic scalpel } \\
\hline - No & $29(87.88)$ & $14(100)$ & $7(100)$ & .443 \\
\hline - Yes & $4(12.12)$ & $0(0)$ & $0(0)$ & \\
\hline \multicolumn{5}{|c|}{ Physicians' experience } \\
\hline - $\leq 25$ years & $19(57.58)$ & $10(71.43)$ & $4(57.14)$ & .716 \\
\hline - $>25$ years & $14(42.42)$ & $4(28.57)$ & $3(42.86)$ & \\
\hline
\end{tabular}

Note. Fisher's exact test was used; Some cells do not add up to the total because of missing values 
The present study had limitations indicating that the results must be interpreted with caution. For example, the small sample size constrained our ability to conduct multivariate analyses to adjust for potential confounders. Furthermore, while the occurrence or absence of facial nerve paralysis was clearly documented in all cases, an objective measure of paralysis such as the House-Brackmann scale was not used in every case. Nevertheless, to the best of our knowledge, this is the first study to describe the factors associated with postparotidectomy facial nerve paralysis in Saudi Arabia. It is also the first to report the effect of using loupes in parotid surgery and the physicians' experience level regarding facial nerve paralysis postparotidectomy.

\section{Conclusions}

The postparotidectomy incidences of temporary and permanent facial nerve paralysis in King Abdulaziz University between 2004 and 2015 were $26 \%$ and $13 \%$, respectively. Tumors concomitantly affecting the superficial and deep lobes and a long operative duration were significantly associated with postparotidectomy facial nerve paralysis.

\section{CONFlicts OF InTEREST Disclosure}

The authors declare they have no conflicts of interest.

\section{REFERENCES}

[1] Ho K, Lin H, Ann DK, et al. An overview of the rare parotid gland cancer. Head Neck Oncol. 2011; 3: 40. PMid: 21917153. https://doi.org/10.1186/1758-3284-3-40

[2] Shah SA, Riaz U, Zubair M, et al. Surgical presentation and outcome of parotid gland tumours. J Coll Physicians Surg Pak. 2013; 23: 625-628. PMid: 24034185.

[3] O'Brien CJ. Current management of benign parotid tumors-the role of limited superficial parotidectomy. Head Neck. 2003; 25: 946-952. PMid: 14603455. https://doi.org/10.1002/hed. 10312

[4] Lin CC, Tsai MH, Huang CC, et al. Parotid tumors: a 10-year experience. Am J Otolaryngol. 2008; 29: 94-100. PMid: 18314019. https://doi.org/10.1016/j.amjoto. 2007.03.002

[5] De Ru JA, van Benthem PP, Hordijk GJ. The location of parotid gland tumors in relation to the facial nerve on magnetic resonance images and computed tomography scans. J Oral Maxillofac Surg. 2002; 60: 992-994. https://doi.org/10.1053/joms. 2002.34402

[6] Fu L, Bundy C, Sadiq SA. Psychological distress in people with disfigurement from facial palsy. Eye (Lond). 2011; 25: 1322-1326. PMid: 21720412. https://doi.org/10.1038/eye.2011.158

[7] Guntinas-Lichius O, Gabriel B, Klussmann JP. Risk of facial palsy and severe Frey's syndrome after conservative parotidectomy for benign disease: analysis of 610 operations. Acta Otolaryngol. 2006; 126: 1104-1109. PMid: 16923718. https://doi.org/10.1080/ 00016480600672618

[8] Yuan X, Gao Z, Jiang H, et al. Predictors of facial palsy after surgery for benign parotid disease: multivariate analysis of 626 operations. Head Neck. 2009; 31: 1588-1592. PMid: 19536764. https://doi.org/10.1002/hed.21134

[9] Bron LP, O'Brien CJ. Facial nerve function after parotidectomy. Arch Otolaryngol Head Neck Surg. 1997; 123: 1091-1096. PMid: 9339986. https://doi.org/10.1001/archotol.1997. 01900100065009
[10] Wierzbicka M, Kopec T, Szyfter W, et al. The presence of facial nerve weakness on diagnosis of a parotid gland malignant process. Eur Arch Otorhinolaryngol. 2012; 269: 1177-1182. PMid: 22179671 https ://doi .org/10.1007/s00405-011-1882-6

[11] Huang CC, Tseng FY, Chen ZC, et al. Malignant parotid tumor and facial palsy. Otolaryngol Head Neck Surg. 2007; 136: 778-782. PMid: 17478215. https://doi.org/10.1016/j.otohns. 2006. 10.043

[12] Preis M, Soudry E, Bachar G, et al. Predicting facial nerve invasion by parotid gland carcinoma and outcome of facial reanimation. Eur Arch Otorhinolaryngol. 2010; 267: 107-111. PMid: 19350259. https://doi.org/10.1007/s00405-009-0968-x

[13] Sood AJ, Houlton JJ, Nguyen SA, et al. Facial nerve monitoring during parotidectomy: a systematic review and meta-analysis. Otolaryngol Head Neck Surg. 2015; 152: 631-637. PMid: 25628369. https://doi.org/10.1177/0194599814568779

[14] Muhanna N, Peleg U, Schwartz Y, et al. Harmonic scalpel assisted superficial parotidectomy. Ann Otol Rhinol Laryngol. 2014; 123: 636-640. PMid: 24707012. https://doi.org/10.1177/000348 9414528674

[15] Grosheva M, Klussmann JP, Grimminger C, et al. Electromyographic facial nerve monitoring during parotidectomy for benign lesions does not improve the outcome of postoperative facial nerve function: a prospective two-center trial. Laryngoscope. 2009; 119: 2299-2305. PMid: 19718745. https://doi.org/10.1002/lary. 20637

[16] Mahmmood VH. Buccal branch as a guide for superficial parotidectomy. J Craniofac Surg. 2012; 23: e447-e449. PMid: 22976701. https://doi.org/10.1097/SCS.0b013e318262d26d

[17] Furusaka T, Tanaka A, Matsuda H, et al. Cervical branch of the facial nerve approach for retrograde parotidectomy compared with anterograde parotidectomy. Acta Otolaryngol. 2014; 134: 1192-1197. PMid: 25315919. https://doi.org/10.3109/00016489.2014. 900701 